\title{
Caracterização da virulência de Magnaporthe grisea em cultivares diferenciadoras japonesas e linhas quase-isogênicas das cultivares IAC-25 e de CO-39 de arroz
}

\author{
Gisele Barata da Silva ${ }^{1}$, Anne Sitarama Prabhu ${ }^{2}$, Marta Cristina Corsi de Filippi ${ }^{2},{ }^{4}$ Leila Garces de Araújo ${ }^{3}$, Laércio \\ Zambolim $^{1}$
}

${ }^{1}$ Universidade Federal de Viçosa, Av. P.H. Rolfs s/n, Campus UFV, CEP 36570-000, Viçosa, MG. E-mail: giselebarata@vicosa.ufv.br. ${ }^{2}$ Embrapa Arroz e Feijão, Caixa Postal 179, CEP 75375-000, Santo Antônio de Goiás, GO, fax: (0xx62) 533-2100, E-mail: prabhu@cnpaf.embrapa.br; ${ }^{3}$ Bolsista $\mathrm{DCR} / \mathrm{CNPq}$

Data da chegada: 21/02/2006. Aceito para publicação em: 06/03/2007.

\section{RESUMO}

Silva, G.B.; Prabhu, A.S.; Filippi, M.C.; Araújo, L.G.; Zambolim, L. Caracterização da virulência de Magnaporthe grisea nas cultivares diferenciadoras japonesas, linhas quase-isogênicas de IAC-25 e CO-39 de arroz. Summa Phytopathologica, v.33, n.4, p.372-377, 2007.

Foi estudada a virulência de 681 isolados de Magnaporthe grisea provenientes de oito lavouras de arroz de terras altas, quatro da cv. BRS Bonança e quatro da cv. Primavera, localizadas em cinco municípios no Estado de Goiás. Foram avaliados 321 isolados de $M$. grisea de folha e de panícula obtidos da cv. BRS Bonança e 360 da cv. Primavera. Para diferenciar a virulência dos isolados foram utilizados nove cultivares diferenciadoras japonesas, seis linhagens quase-isogências (NIL's) da cv. IAC-25, cinco linhagens quase-isogênicas da cv. CO-39, e as cultivares Primavera, BRS Bonança, IAC-25 e CO-39. Os isolados de M. grisea provenientes da cv. BRS Bonança foram mais virulentos nas NIL's de IAC-25 do que isolados da cv. Primavera. A maioria das subpopulações de $M$. grisea provenientes de folhas e panícula, de ambas as cultivares, foram avirulentos à linhagem quase-isogênica CNA-8212. A virulência, em baixa freqüência, foi observada nos isolados de $M$. grisea provenientes de BRS Bonança aos genes Pi-z ${ }^{\mathrm{t}}$ (Toride-1) e de Primavera aos genes Pi-z (Fukunishiki). Uma baixa freqüência de isolados virulentos foram virulentos nas NIL's C101 LAC $(P i-1)$ e C101 A 51(Pi-2). Considerando as reações compatíveis e incompatíveis das NIL's de IAC-25 à população de M. grisea de BRS Bonança, o dendrograma mostrou um grupo ( $90 \%$ de similaridade), diferindo do parental recorrente. Por outro lado, a população de 'Primavera', com exceção da CNA-8199, formou um grupo ( $93 \%$ de similaridade), incluindo o parental recorrente. Os genes de resistência Pi-z e Pi-z das cultivares Fukunishiki e Toride-1, respectivamente, os genes Pi1 e Pi-2 das NIL's de CO-39 e os genes desconhecidos das NIL's IAC25 , que apresentaram maior espectro de resistência às populações estudadas podem ser utilizados no programa de melhoramento, para desenvolvimento de linhas isogênicas de BRS Bonança e Primavera.

Palavras-chave adicionais: Oryza sativa, Pyricularia grisea, brusone.

\section{ABSTRACT}

Silva, G.B.; Prabhu, A.S.; Filippi, M.C.; Araújo, L.G.; Zambolim, L. Characterization of virulence of Magnaporthe grisea on Japanese differentials, near-isogenic lines of IAC-25 and CO-39 of rice. Summa Phytopathologica, v.33, n.4, p.372-377, 2007.

The virulence of the population of Magnaporthe grisea collected from eight upland rice farms of cultivars 'BRS Bonança' and 'Primavera', located in five municipalities in the State of Goiás was studied. A total of 681 isolates, 321 collected from BRS 'Bonança' and 360 from 'Primavera' were utilized for the analysis. The genotypes included for characterizing virulence were nine Japanese race differentials, six near-isogenic lines of 'IAC-25', five nearisogenic lines of ' $\mathrm{CO}-39$ ' and the rice cultivars 'Primavera', 'BRS Bonança', 'IAC-25' and 'CO-39'. The isolates of $M$. grisea from 'BRS Bonança' were more virulent than those of 'Primavera' on NIL's of 'IAC-25'. The majority of isolates from leaf and panicle of both cultivars were avirulent to the near-isogenic line 'CNA 8212'. The virulence was present in low frequency in the pathogen subpopulations of 'BRS Bonança' and 'Primavera' to the genes Pi-z'
(Toride-1) and Pi-z (Fukunishiki) of the Japanese race differentials. A low percentage of isolates were virulent on 'C101 LAC' (Pi-1) e 'C101 A 51'(Pi-2). Considering the compatible and incompatible reactions on the NIL's of 'IAC-25' to the population of $M$. grisea retrieved from 'BRS Bonança', the dedrogram showed one group $(90 \%$ similarity coefficient), distinct from its recurrent parent. On the other hand, the population from 'Primavera', with the exception of 'CNA-8199' formed one group (93\% similarity coefficient), including its recurrent parent. The resistance genes $\mathrm{Pi}-\mathrm{z}$ and $\mathrm{Pi}-\mathrm{z}^{\mathrm{t}}$ of cultivars 'Fukunishiki' and 'Toride-1', respectively, Pi-1 and Pi-2 of NIL's and the unidentified genes in NIL's of 'IAC-25', that showed broad spectrum of resistance to the populations tested can be used for developing near-isogenic lines of rice cultivars 'BRS Bonança' and 'Primavera'.

Additional Keywords: Oryza sativa, Pyricularia grisea, rice blast. 
A brusone do arroz causada por Magnaporthe grisea [Pyricularia grisea Hebert (Barr) (Cooke) Sacc.] é uma espécie complexa e composta por muitos grupos de isolados que divergem quanto a virulência fenotípica.

A maior porcentagem de área plantada no Centro-Oeste é ocupada pelas cvs. Primavera e BRS Bonança, entretanto essas cultivares são suscetíveis à brusone, doença que pode ocorrer nas folhas e nas panículas, causam danos diretos e indiretos em produtividade. Essas cultivares variam em grau de suscetibilidade, sendo que a mais suscetível é a cv. Primavera que apresentou $42,7 \%$ de espiguetas vazias em BRS Bonança foi de apenas $11 \%$, em condições de campo (1). A suscetibilidade da cultivar Primavera vem aumentando com o aumento da área plantada desde seu lançamento em 1996 (13).

O sucesso no manejo da brusone através de cultivares melhoradas para resistência é limitado pela freqüente perda da resistência em condições de campo. A perda de resistência das cultivares é comumente atribuída ao aparecimento de novas raças, ao aumento da taxa de multiplicação de isolados virulentos, aumento do inóculo e área plantada, freqüência de mutação elevada de isolados avirulentos para virulentos $(2,5,10)$, e falha nos métodos de seleção de genótipos que apresentem baixa freqüência de isolados compatíveis (5). Diferentes estratégias de melhoramento têm sido adotadas para o aumento da durabilidade da resistência e estas requerem conhecimentos sobre a estrutura da população do patógeno (17). A análise de virulência dos isolados, obtidos em lavouras comerciais de arroz de terras altas possibilita a incorporação de genes de resistência nas cultivares bem adaptadas às condições locais.

No Japão, Yamada et al. (19) utilizaram nove cultivares com genes conhecidos como diferenciadoras para identificação de raças. Urashima (18), utilizando diferenciadoras japonesas constatou 22 raças em isolados coletados em três cultivares de arroz irrigado no Estado de São Paulo. Tais diferenciadoras não são linhas isogênicas; outros genes desconhecidos podem estar presentes e não descrevem adequadamente a diversidade de virulência nas condições tropicais. Por outro lado, Mackill \& Bonman (12) desenvolveram uma série de linhas quase isogênicas da cultivar CO-39 com genes dominantes de resistência à brusone para caracterização da população do patógeno. Entretanto, o valor desses genes é limitado devido a poucos genes estarem envolvidos na descrição do espectro de virulência da população.

Na Embrapa Arroz e Feijão foi desenvolvida uma série de linhagens quase-isogênicas (NIL's) da cultivar IAC-25, incorporando genes de cultivares exóticas provenientes de arroz indica, com resistência à brusone. Essas linhagens apresentaram moderado ou alto grau de resistência à brusone nas folhas em relação ao progenitor recorrente, nos testes realizados em campo e viveiros de brusone $(6,13$,$) . A$ caracterização da virulência da população de $M$. grisea proveniente das cultivares de terras altas mais plantadas, nas NILs de IAC-25, de CO-39 e nas diferenciadoras japonesas pode fornecer subsídios para os programas de melhoramento da cultura, especificamente pela identificação do material genético que apresenta amplo espectro de resistência, assim como do material já suscetível e que não deve ser utilizado como fonte de resistência.

O objetivo do presente trabalho foi caracterizar a virulência de populações de $M$. grisea provenientes das cultivares BRS Bonança e Primavera, utilizando as diferenciadoras japonesas e as NIL's das cultivares CO-39 e IAC-25.

\section{MATERIAL E MÉTODOS}

Isolados de $M$. grisea foram coletados em oito lavouras comerciais das cultivares de arroz de terras altas, BRS Bonança e Primavera, nos municípios de Piracanjuba (duas lavouras de BRS Bonança), Santo Antônio de Goiás (duas lavouras de Primavera), Uruana (uma lavoura de BRS Bonança), Ceres (uma lavoura de Primavera) e Bela Vista (uma lavoura de BRS Bonança e uma de Primavera), do Estado de Goiás, em dois anos consecutivos (2002 e 2003). Foram feitas coletas de folhas com lesões esporulativas, na fase vegetativa de 30 a 50 dias após o semeio, e de panículas aos 80 a 90 dias após o semeio na fase de enchimento de grãos. A coleção foi composta de 2.082 isolados monospóricos que foram mantidos em discos de papel de filtro esterilizados, acondicionados em sacos de papel e armazenados em freezer $\left(-20^{\circ} \mathrm{C}\right)$.

Para caracterizar a virulência dos isolados foram utilizadas 24 genótipos, as cultivares Primavera, BRS Bonança, IAC-25 e CO-39, seis NIL's da cultivar 'IAC-25'(CNA-2006, CNA-8198, CNA-8199, CNA-8210, CNA-8212, CNA-8209), nove cultivares diferenciadoras japonesas (Shin-2, Aichi- Asahi, Kanto-51, Ishikarishiroke, Tsuyuake, Fukunishiki, Yashiro Mochi, Pi-4, Toride-1) e cinco NIL's da cultivar CO-39 (C.101.LAC, C.101.PKT, C.101.A.51, C.104.PKT, C.105.TTP). Esses genótipos foram semeados em bandejas de plástico $(15 \times 30 \times 10 \mathrm{~cm})$ contendo $3 \mathrm{~kg}$ de solo adubado com NPK (5g de 5$30-15+\mathrm{Zn}$ e $3 \mathrm{~g}$ de sulfato de amônio por $3 \mathrm{~kg}$ de solo). Foram semeados 16 genótipos por bandeja (10 a 12 sementes/cultivar/linha). A adubação de cobertura com nitrogênio foi feita aos 18 dias após o semeio com $2 \mathrm{~g}$ de sulfato de amônio por bandeja.

A inoculação dos 681 isolados de M. grisea, sendo 314 de folha e 367 de panícula, sorteados ao acaso, seguiu a metodologia descrita por Filippi \& Prabhu (7). Plantas de 21 dias de idade foram inoculadas por pulverização com uma suspensão de inóculo $\left(3,0 \times 10^{5}\right.$ conidios. $\left.\mathrm{mL}^{-1}\right)$ sobre as folha, até o ponto de escorrimento, utilizando um atomizador acoplado a um compressor de ar. A inoculação foi repetida quando as plantas testemunhas de arroz apresentaram sintomas da brusone ou quando os isolados de M. grisea não causaram sintomas nas cultivares de origem, BRS Bonança ou Primavera. A reação da brusone nas folhas foi avaliada sete dias após a inoculação, sendo consideradas resistentes as que as plantas que apresentavam lesão do tipo 0 a 3 e suscetíveis as com tipo de lesão 4 a 9 (9).

A virulência, em porcentagem, dos isolados de $M$. grisea foi calculada para cada subpopulação proveniente de folha e de panícula, de ambas as cultivares, considerando a reação da brusone em cada genótipo.

O espectro de virulência dos isolados de $M$. grisea foi analisado com base na similaridade do tipo de reação entre isolados obtidos nas nove diferenciadoras japonesas, nas seis NIL's de IAC-25 e na cultivar IAC-25. Uma matriz binária indicando reação compatível (1) e reação incompatível (0) de cada isolado foi utilizada para construir uma matriz de similaridade entre as diferenciadoras japonesas, as NIL's da cultivar IAC-25 e seu progenitor recorrente de acordo com o coeficiente de similaridade (3). As matrizes de distâncias genéticas foram construídas com base na matriz de similaridade usando o método não ponderado por médias aritméticas (UPGMA), empregando o programa SHAN da Taxonomia Numérica e Análise Multivariada (NTSYS-pc versão 2.0/1997) (16).

\section{RESULTADOS E DISCUSSÃO}

Nas amostras coletadas nas lavouras de arroz de terras altas a maioria dos isolados provenientes das cultivares BRS Bonança e Primavera foram virulentos às diferenciadoras japonesas, com exceção de 'Toride-1' para a população de isolados da cv. 
Tabela 1. Isolados de Magnaporthe grisea, provenientes das folhas da cultivares de arroz Bonança (B) e Primavera (P), virulentos às cultivares diferenciadoras japonesas.

\begin{tabular}{|c|c|c|c|c|c|c|c|c|c|}
\hline \multirow[t]{2}{*}{ Cultivares } & \multirow{2}{*}{$\begin{array}{l}\text { Genes de } \\
\text { resistência }\end{array}$} & \multicolumn{8}{|c|}{ Isolados virulentos (\%) } \\
\hline & & $\begin{array}{c}\mathrm{B} 1^{*} \\
(\mathrm{n}=48)\end{array}$ & $\begin{array}{c}\text { B2 } \\
(n=49)\end{array}$ & $\begin{array}{c}\text { B3 } \\
(n=48)\end{array}$ & $\begin{array}{c}\text { B4 } \\
(n=38)\end{array}$ & $\begin{array}{c}\mathrm{P} 1{ }^{*} \\
(\mathrm{n}=48)\end{array}$ & $\begin{array}{c}P 2 \\
(n=46)\end{array}$ & $\begin{array}{c}\text { P3 } \\
(n=45)\end{array}$ & $\begin{array}{c}\mathrm{P} 4 \\
(\mathrm{n}=45)\end{array}$ \\
\hline Shin-2 & $\mathrm{Pi}-\mathrm{k}^{5}$ & 89,58 & 87,76 & 100,00 & 89,47 & 81,25 & 67,39 & 73,33 & 65,91 \\
\hline Aichi- Asahi & Pi-a & 87,50 & 85,71 & 66,67 & 71,05 & 93,75 & 86,96 & 75,56 & 70,45 \\
\hline Ishikarishiroke & $\mathrm{Pi}-\mathrm{i}$ & 87,50 & 89,80 & 97,92 & 94,74 & 97,92 & 93,48 & 95,56 & 93,18 \\
\hline Kanto-51 & $\mathrm{Pi}-\mathrm{k}$ & 79,17 & 93,88 & 87,50 & 89,47 & 97,92 & 93,48 & 93,33 & 95,45 \\
\hline Tsuyuake & $\mathrm{Pi}-\mathrm{k}^{\mathrm{m}}$ & 39,58 & 83,67 & 4,17 & 68,42 & 81,25 & 84,78 & 95,56 & 90,91 \\
\hline Fukunishiki & $\mathrm{Pi}-\mathrm{z}$ & 83,33 & 75,51 & 91,67 & 78,95 & 10,42 & 15,22 & 37,78 & 6,82 \\
\hline Yashiro Mochi & Pi-ta & 85,42 & 83,67 & 35,42 & 92,11 & 93,75 & 67,39 & 77,78 & 77,27 \\
\hline $\mathrm{Pi}-4$ & $\mathrm{Pi}-\mathrm{ta}^{2}$ & 85,42 & 91,84 & 97,92 & 94,74 & 100,00 & 89,13 & 97,78 & 97,73 \\
\hline Toride-1 & $\mathrm{Pi}-\mathrm{z}^{\mathrm{t}}$ & 27,08 & 18,37 & 2,08 & 18,42 & 85,42 & 78,26 & 42,22 & 29,55 \\
\hline
\end{tabular}

$\mathrm{n}=$ tamanho da amostra

* B1 a B4 e P1 a P4, diferentes lavouras onde foram coletadas folhas e panículas infectadas pela brusone.

Tabela 2. Isolados de Magnaporthe grisea, provenientes das panículas das cultivares de arroz Bonança (B) e Primavera (P), virulentos às cultivares diferenciadoras japonesas.

\begin{tabular}{|c|c|c|c|c|c|c|c|c|c|}
\hline \multirow[t]{2}{*}{ Cultivares } & \multirow{2}{*}{$\begin{array}{l}\text { Genes de } \\
\text { resistência }\end{array}$} & \multicolumn{8}{|c|}{ Isolados virulentos (\%) } \\
\hline & & $\begin{array}{c}\text { B1 } \\
(n=33)\end{array}$ & $\begin{array}{c}\text { B2 } \\
(n=30)\end{array}$ & $\begin{array}{c}\text { B3 } \\
(n=47)\end{array}$ & $\begin{array}{c}\mathrm{B} 4 \\
(\mathrm{n}=28)\end{array}$ & $\begin{array}{c}P 1 \\
(n=47)\end{array}$ & $\begin{array}{c}\mathrm{P} 2 \\
(\mathrm{n}=43)\end{array}$ & $\begin{array}{c}P 3 \\
(n=43)\end{array}$ & $\begin{array}{c}\mathrm{P} 4 \\
(\mathrm{n}=43)\end{array}$ \\
\hline Shin-2 & $\mathrm{Pi}-\mathrm{k}^{5}$ & 60,00 & 65,91 & 87,23 & 97,44 & 59,09 & 47,37 & 69,05 & 71,43 \\
\hline Aichi- Asahi & Pi-a & 66,00 & 72,73 & 72,34 & 51,28 & 65,91 & 84,21 & 35,71 & 59,52 \\
\hline Ishikari & $\mathrm{Pi}-\mathrm{i}$ & 86,00 & 84,09 & 95,74 & 87,18 & 90,91 & 100,00 & 73,81 & 88,10 \\
\hline Kanto-51 & Pi-k & 60,00 & 84,09 & 85,11 & 100,00 & 93,18 & 100,00 & 97,62 & 100,00 \\
\hline Tsuyuake & $\mathrm{Pi}-\mathrm{k}^{\mathrm{m}}$ & 20,00 & 81,82 & 38,30 & 82,05 & 61,36 & 89,47 & 83,33 & 90,48 \\
\hline & & 32,00 & 45,45 & 48,94 & 64,10 & 4,55 & 7,89 & 2,38 & 16,67 \\
\hline Yashiro Mochi & Pi-ta & 38,00 & 25,00 & 80,85 & 89,74 & 43,18 & 15,79 & 95,24 & 83,33 \\
\hline $\mathrm{Pi}-4$ & Pi-ta ${ }^{2}$ & 68,00 & 81,82 & 93,62 & 100,00 & 84,09 & 89,47 & 97,62 & 92,86 \\
\hline Toride-1 & $\mathrm{Pi}-\mathrm{z}^{\mathrm{t}}$ & 12,00 & 9,09 & 6,38 & 46,15 & 59,09 & 28,95 & 57,14 & 50,00 \\
\hline
\end{tabular}

* B1 a B4 e P1 a P4, diferentes lavouras onde foram coletadas folhas e panículas infectadas pela brusone.

Tabela 3. Isolados de Magnaporthe grisea, provenientes de folhas das cultivares de arroz Bonança (B) e Primavera (P), virulentos às linhas quaseisogênicas (NIL's) da cultivar IAC-25.

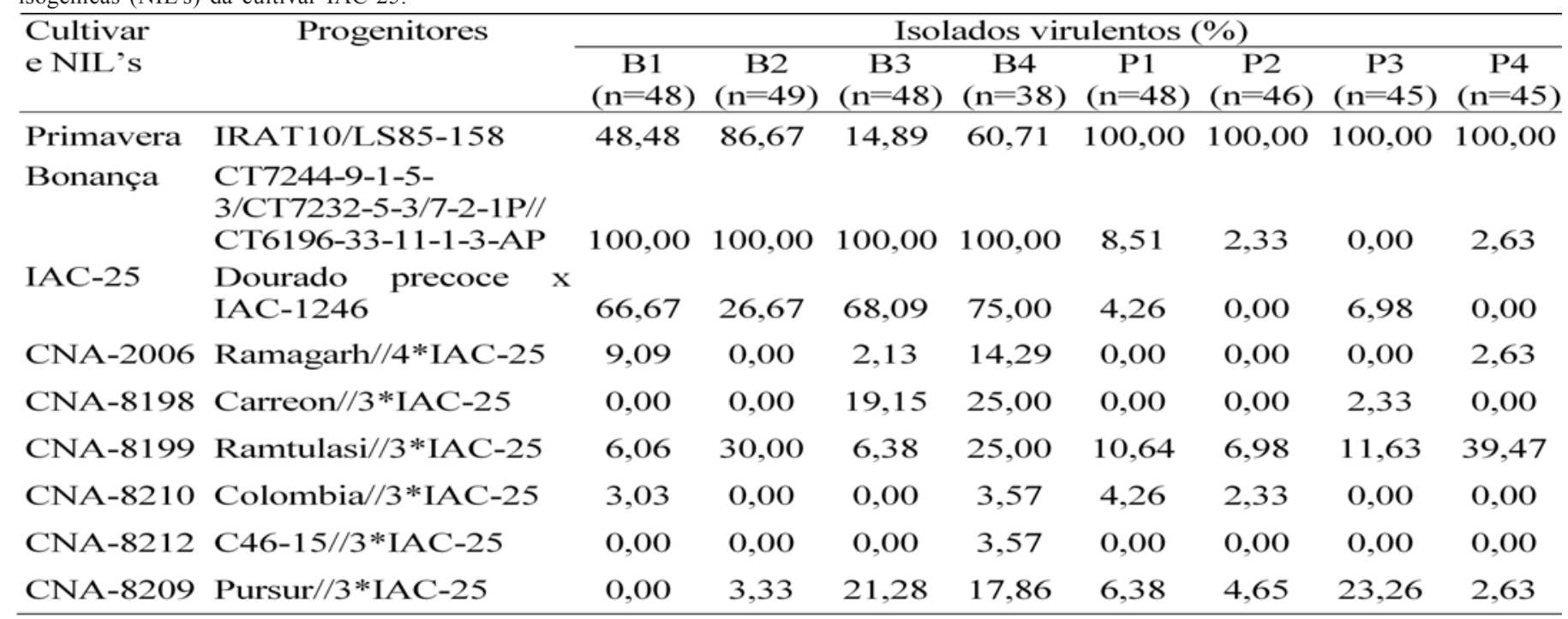

$\mathrm{n}=$ tamanho da amostra

* B1 a B4 e P1 a P4, diferentes lavouras onde foram coletadas folhas e panículas infectadas pela brusone. 
Tabela 4. Isolados de Magnaporthe grisea, provenientes de panículas das cultivares de arroz Bonança (B) e Primavera (P), virulentos às linhas quaseisogênicas (NIL's) da cultivar IAC-25.

\begin{tabular}{|c|c|c|c|c|c|c|c|c|c|}
\hline \multirow{2}{*}{$\begin{array}{l}\text { Cultivar e } \\
\text { NIL's }\end{array}$} & \multirow[t]{2}{*}{ Progenitores } & \multicolumn{8}{|c|}{ Isolados virulentos (\%) } \\
\hline & & $\begin{array}{c}\mathrm{B} 1 \\
(\mathrm{n}=33)\end{array}$ & $\begin{array}{c}\text { B2 } \\
(\mathrm{n}=30)\end{array}$ & $\begin{array}{c}\text { B3 } \\
(n=47)\end{array}$ & $\begin{array}{c}\text { B4 } \\
(n=28)\end{array}$ & $\begin{array}{c}P 1 \\
(n=47)\end{array}$ & $\begin{array}{c}\mathrm{P} 2 \\
(\mathrm{n}=43)\end{array}$ & $\begin{array}{c}\text { P3 } \\
(\mathrm{n}=43)\end{array}$ & $\begin{array}{c}\mathrm{P} 4 \\
(\mathrm{n}=43)\end{array}$ \\
\hline Primavera & IRAT10/LS85-158 & 10,00 & 81,58 & 25,53 & 74,36 & 86,36 & 73,68 & 64,29 & 90,48 \\
\hline Bonança & CT7244-9-1-5-3/CT7232-5-3/7-2-1P// CT6196-33-11-1-3-AP & 12,00 & 34,21 & 53,19 & 84,62 & 0,00 & 2,63 & 4,76 & 9,52 \\
\hline IAC- 25 & Dourado precoce x IAC-1246 & 10,00 & 42,11 & 40,43 & 17,95 & 0,00 & 2,63 & 2,38 & 0,00 \\
\hline CNA-2006 & Ramagarh $/ / 4 *$ IAC- 25 & 0,00 & 0,00 & 2,13 & 2,56 & 0,00 & 0,00 & 0,00 & 0,00 \\
\hline CNA-8198 & Carreon $/ / 3 *$ IAC- 25 & 4,00 & 7,89 & 4,26 & 7,69 & 2,27 & 0,00 & 2,38 & 2,38 \\
\hline CNA-8199 & Ramtulasi//3*IAC- 25 & 0,00 & 2,63 & 6,38 & 7,69 & 4,55 & 0,00 & 16,67 & 26,19 \\
\hline CNA-8210 & Colombia $/ / 3 *$ IAC- 25 & 4,00 & 0,00 & 0,00 & 2,56 & 0,00 & 0,00 & 2,38 & 2,38 \\
\hline CNA-8212 & C46-15//3*IAC- 25 & 0,00 & 0,00 & 0,00 & 0,00 & 0,00 & 0,00 & 0,00 & 0,00 \\
\hline CNA-8209 & Pursur $/ / 3 *$ IAC-25 & 8,00 & 13,16 & 4,26 & 12,82 & 4,55 & 2,63 & 4,76 & 2,38 \\
\hline
\end{tabular}

$\mathrm{n}=$ tamanho da amostra

* B1 a B4 e P1 a P4, diferentes lavouras onde foram coletadas folhas e panículas infectadas pela brusone.

Bonança e 'Fukunishiki' para a população obtida da cv. Primavera (Tabelas 1 e 2).

Foram observados padrões distintos de virulência para os isolados de $M$. grisea coletados em folhas e panículas nas NIL's de IAC-25. Amplo espectro de virulência foi detectado com os isolados provenientes de folhas, de ambas as cultivares, enquanto que os isolados provenientes de panículas obtiveram baixo espectro de virulência (Tabelas 3 e 4).

Entre os isolados de BRS Bonança, a virulência foi mais elevada na cultivar IAC-25 do que nas NIL's de IAC-25, indicando que os genes introduzido nas NIL's de IAC-25 são efetivos contra isolados provenientes da cv. Bonança. Entretanto existiu variação quanto ao grau de resistência entre as NIL's de IAC-25, a CNA 8199 foi a mais suscetível aos isolados obtidos de folhas da cv. Bonança, e a CNA8212 foi altamente resistente, tanto para isolados de folhas e de panículas provenientes de ambas as cultvares. O baixo grau na freqüência de virulência nesse genótipo (CNA-8212) indica que o mesmo possui amplo espectro de resistência às populações de $M$. grisea coletados. No entanto, já existem isolados, em baixa freqüência, virulentos a esse gene de resistência, embora esse genótipo nunca tenha sido plantado em grande escala.

A freqüência de isolados virulentos provenientes das lavouras de BRS Bonança, em média, foi maior do que os isolados de Primavera em todas as NIL's testadas e na cultivar IAC-25. As NIL's CNA8212, CNA-8210 e CNA-2006 apresentaram maior resistência aos isolados de lavouras de BRS Bonança. Com exceção das NIL's CNA8209 e CNA-8198, todas as outras NIL's e a cultivar IAC-25 apresentaram elevado grau de resistência aos isolados de Primavera.

Foi elevada a freqüência de isolados de folha virulentos à cultivar CO-39 e às NIL's C101 PKT (Pi-4a), C104 PKT (Pi-3) e C 105 TTP $(P i-4 b)$, independentemente da cultivar de origem (Tabela 5). Uma baixa freqüência de isolados virulentos foi detectado às NILS C.101.LAC $(P i-1)$ e C.101.A.51 $(P i-2)$, variando de $0 \%$ a $27,59 \%$ para $P i-1$ e para $P i-2$ de $3,45 \%$ a $54,17 \%$. A NIL C.101.LAC apresentou maior grau de resistência que C.101.A.51, para isolados provenientes das cultivares Bonança e de Primavera (Tabela 6). Dentre os isolados testados, nove isolados foram virulentos para ambos os genes $\mathrm{Pi}-1 \mathrm{e}$ $P i-2$. Em lavouras de arroz irrigado, no estado do Tocantins, foram

Tabela 5. Isolados de Magnaporthe grisea provenientes de folhas de quatro lavouras de arroz da cultivar Bonança e quatro de Primavera, virulentos aos genes conhecidos das linhas quase isogênicas (NIL's) de CO-39.

\begin{tabular}{|c|c|c|c|c|c|c|c|c|c|}
\hline \multirow[t]{2}{*}{ Genótipos } & \multirow{2}{*}{$\begin{array}{l}\text { Genes de } \\
\text { resistência }\end{array}$} & \multicolumn{8}{|c|}{ Isolados virulentos (\%) } \\
\hline & & $\begin{array}{c}\mathrm{B} 1^{(4)} \\
(\mathrm{n}=33)\end{array}$ & $\begin{array}{c}\mathrm{B} 2^{(4)} \\
(\mathrm{n}=29)\end{array}$ & $\begin{array}{c}\mathrm{B}^{(4)} \\
(\mathrm{n}=44)\end{array}$ & $\begin{array}{c}\mathrm{B} 4^{(4)} \\
(\mathrm{n}=24)\end{array}$ & $\begin{array}{c}P 1^{(4)} \\
(n=46)\end{array}$ & $\begin{array}{c}\mathrm{P} 2^{(4)} \\
(\mathrm{n}=46)\end{array}$ & $\begin{array}{c}\mathrm{P}^{(4)} \\
(\mathrm{n}=47)\end{array}$ & $\begin{array}{c}\mathrm{P} 4^{(4)} \\
(\mathrm{n}=30)\end{array}$ \\
\hline C.101.LAC ${ }^{(1)}$ & Pi-1 & 15,15 & 27,59 & 0,00 & 16,67 & 8,70 & 11,36 & 19,15 & 26,67 \\
\hline C.101.PKT ${ }^{(1)}$ & $\mathrm{Pi}-4 \mathrm{a}$ & 93,94 & 79,31 & 100,00 & 75,00 & 91,30 & 79,55 & 61,70 & 83,33 \\
\hline C.101.A. $51^{(1)}$ & $\mathrm{Pi}-2$ & 9,09 & 3,45 & 36,36 & 54,17 & 21,74 & 9,09 & 19,15 & 43,33 \\
\hline C.104.PKT ${ }^{(1)}$ & $\mathrm{Pi}-3$ & 84,85 & 75,86 & 100,00 & 83,33 & 56,52 & 72,73 & 63,83 & 83,33 \\
\hline C.105.TTP ${ }^{(1)}$ & $\mathrm{Pi}-4 \mathrm{~b}$ & 96,97 & 79,31 & 100,00 & 66,67 & 91,30 & 86,36 & 68,09 & 90,00 \\
\hline $\mathrm{CO}-39^{(2)}$ & - & 96,97 & 75,86 & 97,73 & 75,00 & 89,13 & 79,55 & 53,19 & 90,00 \\
\hline Primavera $^{(3)}$ & - & 42,42 & 62,07 & 13,64 & 29,17 & 100,00 & 100,00 & 100,00 & 96,67 \\
\hline Bonança $^{(3)}$ & - & 100,00 & 100,00 & 100,00 & 95,83 & 8,70 & 0,00 & 0,00 & 0,00 \\
\hline
\end{tabular}

(1) NIL'. ${ }^{(2)}$ Parental recorrente. ${ }^{(3)}$ Cultivares comerciais de arroz. Designação da lavoura de B = Bonança e $\mathrm{P}=$ Primavera e, $\mathrm{n}=$ tamanho da amostra

* B1 a B4 e P1 a P4, diferentes lavouras onde foram coletadas folhas e panículas infectadas pela brusone. 
Tabela 6. Isolados de Magnaporthe grisea provenientes de lavouras das cultivares de arroz Bonança e Primavera, que mostraram reação diferencial em duas NIL's da cultivar CO-39.

\begin{tabular}{lccc}
\hline Cultivar de origem & C.101.LAC & C.101.A.51 & Total de isolados \\
\hline Bonança & $\mathrm{R}$ & $\mathrm{S}$ & 29 \\
Bonança & $\mathrm{S}$ & $\mathrm{R}$ & 14 \\
Bonança & $\mathrm{S}$ & $\mathrm{S}$ & 1 \\
Primavera & $\mathrm{R}$ & $\mathrm{S}$ & 26 \\
Primavera & $\mathrm{S}$ & $\mathrm{R}$ & 10 \\
Primavera & $\mathrm{S}$ & $\mathrm{S}$ & 8 \\
\hline
\end{tabular}

$* \mathrm{R}=$ Resistentes (0-3); $\mathrm{S}=$ Suscetível (4- 9)

A

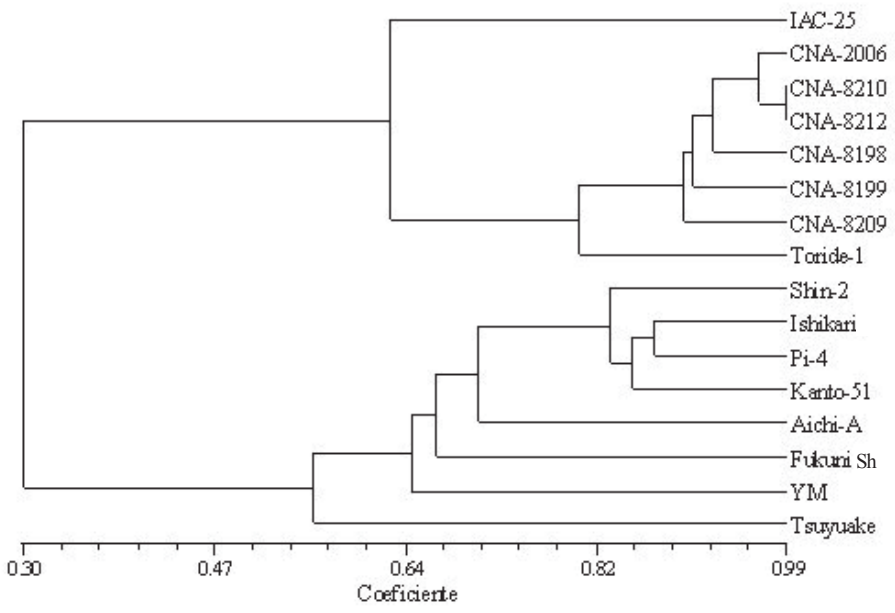

B

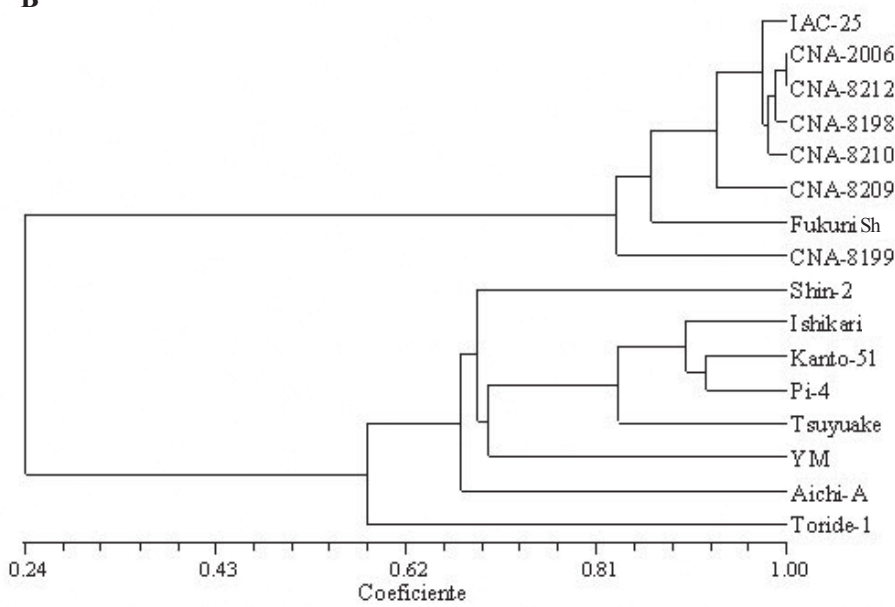

Figura 1.Dendrograma das diferenciadoras japonesas, das NIL's de IAC25 e de seu progenitor recorrente, baseado no coeficiente de similaridade de Match; os dados das reações compatíveis e incompatíveis às populações de Magnaporthe grisea provenientes de lavouras Bonança (A) e Primavera (B), foram utilizadas nas análises; escala representa coeficiente de similaridade.

coletados isolados da cultivar Metica-1 e verificado que os genes $\mathrm{Pi}-1$ e $P i-2$ foram efetivos contra a população de $M$. grisea dessa cultivar (8). De acordo com Chen et al. (3) o gene $P i$-2 possui amplo espectro de resistência e em combinação com o gene $P i$ - 1 tem demonstrado amplo espectro de resistência para a maioria das populações de isolados de $M$. grisea provenientes das Filipinas. O uso dessas diferenciadoras com combinação de genes de resistência tem importância na detecção de genes de avirulência no patógeno. Assim como no presente trabalho os estudos realizados por Kumar et al. (11) e Filippi \& Prabhu (7) tem demonstrado que o espectro de resistência das linhagens com os genes $P i-1$ e $P i-2$ é amplo.

Na natureza, há preexistência de isolados compatíveis a genes de resistência mesmo que esses genes nunca tenham sido utilizados em larga escala $(6,13,15)$. A cv Primavera é suscetível à maioria dos isolados provenientes da cv. BRS Bonança, mas isolados da cv. Primavera são pouco virulentos à $\mathrm{cv}$. BRS Bonança. Isto pode ser explicado devido a cultivar Primavera apresenta base genética mais restrita que Bonança e assim como pela cultivar Primavera ser amplamente plantada em grandes áreas desde de seu lançamento comparada com Bonança $(1,14,17)$. O grau de resistência das NIL's, tanto de IAC-25 quanto de CO-39, foi influenciada mais pela cultivar de origem do isolado de $M$. grisea.

Os coeficientes de similaridade entre as NIL's da cv. IAC-25 e as cultivares diferenciadoras japonesas, com genes conhecidos, com base nas reações compatíveis e incompatíveis são apresentados na Figura 1. Para a população de $M$. grisea de BRS Bonança, as NIL's de IAC25 formaram um grupo com similaridade de $90 \%$, diferindo de seu progenitor recorrente IAC-25. Em geral, as NIL's originadas da cv. IAC-25, com diferentes genes de resistência incorporados, são mais efetivos para diferenciar população de $M$. grisea provenientes da cv. BRS Bonança em relação às diferenciadoras japonesas, as quais não formaram um grupo distinto. Entretanto, a cv.Toride-1, pode ser incluída em um grupo com as NIL's de IAC-25 com $80 \%$ de similaridade, possivelmente que a população de $M$. grisea de BRS Bonança não consegue superar a resistência do gene $\mathrm{Pi}-\mathrm{Z}^{\mathrm{t}}$ presente nessa cultivar.

Para a população de $M$. grisea obtida da cv. Primavera, a cultivar IAC-25 e suas NIL's, com exceção da CNA 8199, formaram um grupo com mais de $90 \%$ de similaridade. Entre as diferenciadoras japonesas somente 'Fukunishiki', possui similaridade em mais de $85 \%$ com as NIL's de IAC-25 e seu progenitor recorrente (IAC-25).

Baixa freqüência de isolados virulentos, provenientes da cv.Bonança, foi detectada na cv. Toride-1 (Pi- $\mathrm{Z}^{\mathrm{t}}$ ), assim como de isolados obtidos da cv. Primavera na cv. Fukunishiki (Pi-z).

Os genes de resistência Pi-z e Pi- $\mathrm{z}^{t}$ presentes nas cultivares Fukunishiki e Toride-1, e os genes desconhecidos das NIL's IAC-25 (CNA 8212, CNA 8210 e CNA 8198), que apresentaram maior espectro de resistência contra as populações estudadas podem ser usados no programa de melhoramento para obtenção de isolinhas de BRS Bonança e Primavera com genes de resistência diversificados. Os métodos e as estratégias atualmente adotadas para obtenção de cultivares resistentes podem ser melhoradas através da reintrodução de diversidade de resistência genética contra as populações do patógeno mais freqüentes das cultivares BRS Bonança e Primavera. 


\section{REFERÊNCIAS BIBLIOGRÁFICAS}

1. Araujo, L.G.; Prabhu, A.S.; Oliveira, C.F.; Berni, R.F. Efeito da brusone nas panículas nos componentes de produtividade nas cultivares de arroz Primavera e Bonança. Summa Phytopathologica, Piracicaba, v.30, p.265-270, 2004.

2. Bonman, J.M.; Khush, G.S.; Nelson, R.J. Breeding rice for resistance to pests. Annual Review of Phytopathology, Palo Alto, v.30, p.507-528, 1992.

3. Chen, D. H., Zeigler, R. S., Ahn, S. W. Nelson, R. J. Phenotypic charachterization of the rice blast resistance gene Pi2(t). Plant disease, v.80, p. 52-56. 1996.

4. Clifford H.; Stephenson W. An introduction to numerical classification. London: Academic Press, 1975. 229p.

5. Correa-Victoria, F.J.; Zeigler, R.S. Pathogenic variability analysis of Pyricularia grisea at rice blast "hot-spot" breeding site in Eastern Colombia. Plant Disease, St. Paul, v.77, p.1029-1035, 1993.

6. Filippi, M.C.; Prabhu, A.S. Avaliação de linhagens melhoradas de IAC 25 e IRAT 112 para resistência estável aos isolados de Pyricularia grisea. Fitopatologia Brasileira, Brasília, v.20, p.303, 1995. (Resumo).

7. Filippi, M.C.; Prabhu, A.S. Phenotypic virulence analysis of Pyricularia grisea isolates from Brazilian upland rice cultivars. Pesquisa Agropecuária Brasileira, Brasília, v.36, p.27-35, 2001.

8. Filippi, M.C.; Prabhu, A.S.; Araujo, L.G.; Faria, J.C. Genetic diversity and virulence pattern in field populations of Pyricularia grisea from rice cultivar Metica1. Pesquisa Agropecuária Brasileira, Brasília, v.37, p.1681-1688, 2002.

9. INTERNATIONAL RICE RESEARCH INSTITUTE. Standard evaluation system for rice. $3^{\text {rd }}$ ed. Los Baños, 54 p. 1988.

10. KIYOSAWA, S. Genetics and epidemiological modeling of bre- akdown of plant disease resistance. Annual Review of Phytopathology, Palo Alto, v.20, p.93-117, 1982.

11. Kumar, J.; Nelson, R.J.; Zeigler, R.S. Population structure and dynamics of Magnaporthe grisea in the Indian Himalayas. Genetics, Maryland, v.152, p.971-984, 1999.

12. Mackill, D.J.; Bonman, J.M. Inheritance of blast resistance in near isogenic lines of rice. Phytopathology, St. Paul, v.82, p.746749, 1992.

13. Prabhu, A.S.; Castro, E. da M. de; Araujo, L.G.; Berni, R.F. Resistance spectra of six elite breeding lines of upland rice to Pyricularia grisea. Pesquisa Agropecuária Brasileira, Brasília, v.38, p.203-210, 2003.

14. Prabhu, A.S.; Filippi, M.C.; Araujo, L.G. Pathotype diversity of Pyricularia grisea from improved upland rice cultivars in experimental plots. Fitopatologia Brasileira, Brasília, 2002.

15. Prabhu, A.S.; Morais, O.P. de; Castro, E. da M. de; Guimarães, E.P. Novas linhagens de IAC-25 e IRAT 112 resistentes à brusone. In: EMBRAPA. Centro Nacional de Pesquisa de Arroz e Feijão (Goiânia, GO). Relatório Técnico do Centro Nacional de Pesquisa de Arroz e Feijão 1990/1992. Goiânia, 1994. p.104. (EMBRAPA-CNPAF. Documentos, 51).

16. Rohlf, F.J. NTSYS-pc: numerical taxonomy and multivariate analysis system. Version 1.80. New York: Exeter Software, 1993

17. Silva, G. B. Estrutura populacional de Pyricularia grisea (Cooke) Saac. em folha e panículas de arroz de terras altas. UFV. ViçosaMG, Tese doutorado, 2004. $67 \mathrm{p}$.

18. Urashima, A.S. Variation in virulence in the rice blast fungus Magnaporthe grisea in São Paulo State. Pesquisa Agropecuária Brasileira, Brasília, v.37, p.109-115, 2002.

19. Yamada, M.; Kiyosawa, S.; Yamaguchi, T.; Hirano, T.; Kobayashi, K.; William, E.F. Proposal for a new method for differentiating races of Pyricularia oryzae Cavara in Japan. Annual Phytopathology Society of Japan, Tokyo, v.42, p.216-219, 1976. 